\title{
The Combination of Laser and Nanoparticles for Enamel Protection: An In Vitro Study
}

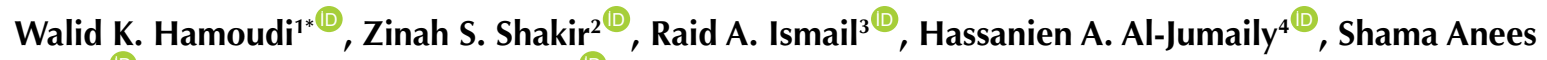 \\ Sahib $^{5^{\circledR}}$, Abdullah R. Abedulwahhab ${ }^{6^{\mathbb{D}}}$
}

${ }^{1}$ Al-Farabi University College, Department of Optics Techniques, Baghdad, Iraq

${ }^{2} \mathrm{Al}$-Farabi University College, Department of Optics Techniques, Baghdad, Iraq

${ }^{3}$ University of Technology, Department of Applied Science, Baghdad, Iraq

${ }^{4}$ University of Baghdad, Collage of Dentistry, Department of Oral and Maxillofacial Surgery, Baghdad, Iraq

${ }^{5}$ Al-Rafidain University College, Department of Dentistry, Baghdad, Iraq

${ }^{6} \mathrm{Al}$ Hikma University College, Department of Medical Devices Techniques, Baghdad, Iraq

\section{*Correspondence to}

Walid K. Hamoudi,

Email: wjuaini2007@yahoo.com

Received: March 27, 2021 Accepted: October 26, 2021 Published online 26 December 2021

\begin{abstract}
Introduction: Dental decay is caused by the fermentation of carbohydrates and the production of acids which demineralize teeth. The fermented food debris lowers the $\mathrm{pH}$ under 5.5, resulting in the mineral loss of teeth. Anti-decay factors are used to reduce decay rates and increase dental protection.

Methods: Fifteen sectioned teeth samples were immersed in Ag NPs solution and then irradiated with laser pulses. Structures, morphologies, chemical compositions and microhardness were studied using the Vickers micro-hardness tester, energy dispersive $\mathrm{x}$-ray machine, atomic force microscope and scanning electron microscopes.

Results: Nine mature extracted human third molars, cleaned and placed in plastic molds then filled with a warm epoxy resin, were sectioned longitudinally and polished. The samples were then cleaned ultrasonically and stored in distilled water and taken immediately one by one for laser treatment. Sharper, overlapping, interconnected rods and higher resistance against enamel decay were demonstrated with little alterations of the mineral percentages of the teeth samples.

Conclusion: The combination of laser light and silver annoparticles improved the decay resistance; where regular inter-connected chain-like merged grains were formed. These laser-induced modifications in enamel components have reduced the lattice stress and enamel solubility and improved resistance against decay. The computer model indicated a possible prediction of the lasertreated profile prior to laser treatment.

Keywords: Dental caries; Enamel resistance; Demineralization; Nd: YAG Laser; Silver nanoparticles.
\end{abstract}

\section{Introduction}

Dental caries is the local destruction of dental tissue by the bacterial leavening of sugars. The fermentation process of the carbohydrates produces acids that cause the enamel to demineralize. ${ }^{1}$ During the demineralization process, calcium and phosphate ions are transferred into the bordering environment, leaving a cavity in the demineralized zone. ${ }^{2}$ Repeated ingestion of fermentable food keeps the $\mathrm{pH}$ below 5.5, which causes a loss of dental minerals. The demineralization can be developed into the dentine down to the pulp where it causes severe pain due to pulpitis or periapical lesion. ${ }^{3}$ The expansion of the anti-caries factors can diminish decay rates and increase dental protection. Chemotherapeutic agents such as metal ions, fluoride agents, and antibiotics have been tested for protecting teeth and arresting caries. ${ }^{4,5}$ Nano silver fluoride (NSF) was developed as an efficient anticaries factor. ${ }^{6}$ The laser was used in dentistry years ago to enhance dental enamel resistance to demineralization and improve its properties. ${ }^{7}$ The first suggestion to use ruby laser irradiation for inhibition of dental caries was in $1972^{8}$; after that, the laser became available for dental treatment, specified with its efficiency, easiness, and comfortableness. ${ }^{9}$ The whole idea is based on laser interaction with dental hard tissues. This depends on the tissue optical properties and laser wavelength, fluence, mode of operation and polarization state. ${ }^{10}$ Tooth resistance to mineral loss, caused by acids, can be enhanced by combining the effect of the laser with remineralizing agent treatments. ${ }^{11}$ In the past, silver was used as an antibacterial element, but it has been replaced by antibiotics in the present time. Silver was put again in use because of the high resistance of pathogens to antibiotics. ${ }^{12}$ The main goal of integrating silver NPs into dental materials is to minimize the formation of biofilm and microbial colonization. ${ }^{13}$ To prevent caries, dental 
enamel must be made more resistant and less soluble. In laser dental treatment, the incident laser energy has to be absorbed efficiently and converted into heat without affecting the surrounding and deeper tissue. ${ }^{14}$ Researchers are concerned with the effect of the focused laser beam on the melting and re-solidification of the illuminated dental tissue. ${ }^{15-17}$ Enamel fusing and fusion are responsible for the enhancement of enamel resistance against caries. ${ }^{18,19}$ Laser illumination forms pyrophosphates; decreases water and carbonate components, increases the contents of hydroxyl ions, and dissociates proteins. These additional changes can reduce enamel solubility. ${ }^{20-22}$ Other studies have demonstrated size and shape changes in hydroxyapatite crystals after laser irradiation. ${ }^{23-25}$ The effect of physicochemical changes in enamel showed a growing resistance to decay..$^{16}$ We report a novel technique to increase the dental enamel resistance against tooth decay by using Nd: YAG and diode lasers combined with colloidal silver nanoparticles. A computer model was written to help predict the exact laser-treated volume under the enamel surface.

\section{Materials and Methods}

Nine mature extracted human third molars, in good dental health, were stored in $10 \%$ formalin. ${ }^{26}$ The teeth were washed and their attached tissue was removed by an ultrasonic cleaner (Lab Tech, Daihanlabtech co., LTD, model LUC-410, Korea), and then they were brushed with toothpaste. The teeth were placed in plastic molds and a warm epoxy resin was poured. After a couple of hours, the teeth were sectioned longitudinally and polished to level up the exposed area, using a low-speed grinding machine under water-cooling and Amery silicon carbide papers (No. 1500 to 3000). After that, 0.05 polishing alumina and a cloth were used in a low-speed metallurgical polisher (DP-U4, Struers-Denmark) to obtain smooth surfaces. Finally, the samples were cleaned ultrasonically for 5 minutes and stored in distilled water, and they were taken immediately one by one for laser treatment. A Q-switched Nd: YAG laser (HUAFEL, Single Pulse Mode - China), operating at a 1064-nm wavelength and providing up to $1 \mathrm{~J}, 9 \mathrm{~ns}$ laser pulses of $0.8 \mathrm{~mm}$ diameter, and a 3.6-W-continuous (CW) diode laser, operating at an 808 $\mathrm{nm}$ wavelength, were employed to irradiate $(3 \times 3) \mathrm{mm}^{2}$ of the tooth samples' surfaces. The silver nano-colloidal solution was prepared by chemical reduction of silver nitrate $\left(\mathrm{AgNO}_{3}\right)$ with sodium boro-hydride $\left(\mathrm{NaBH}_{4}\right)$. A beaker containing $60 \mathrm{~mL}$ of $0.002 \mathrm{M}\left(\mathrm{NaBH}_{4}\right)$ was placed in an ice bath (to slow the reaction) and stirred for about 30 minutes by a magnetic stirrer. During this time, $4 \mathrm{~mL}$ of $0.001 \mathrm{M}\left(\mathrm{AgNO}_{3}\right)$ was added to the solution at a rate of one drop per second. The yellow transparent solution appeared as a nano-colloidal silver suspension with an absorption peak at $400 \mathrm{~nm}$ and a particle size ranging between 25-50 nm, measured by SEM. The temperature rise was measured on two tooth samples during one minute of diode laser irradiation. This was accomplished by using a digital infrared thermometer AR350+ (Smart Sensor, Intell Instruments Plus, China). This test was important to ensure a pulp temperature rise within the safety limit $\left(5.5^{\circ} \mathrm{C}\right) .^{27}$

Fifteen tooth samples were randomly divided into five groups; each comprises 3 samples, according to the treatment parameters. Group 1 was the untreated control group. The samples of group 2 were treated with 5 pulses of the $100 \mathrm{~mJ} \mathrm{Nd:YAG} \mathrm{laser} \mathrm{while} \mathrm{they} \mathrm{were} \mathrm{immersed}$ in the colloidal silver nano-particles solution, followed by 3.6W diode laser illumination for 1 minute. Group 3 was treated with a single pulse of the $500 \mathrm{~mJ} \mathrm{Nd}$ : YAG laser combined with colloidal silver nano-particles solution and then by a $3.6 \mathrm{~W}$ diode laser for 1 minute. Group 4 was illuminated with a single $500 \mathrm{~mJ}$ laser pulse from the Nd: YAG laser and then by a combined 3.6 W diode laser - colloidal silver nano-particles solution for 1 minute. Finally, group 5 was illuminated by a $3.6 \mathrm{~W}$ diode laser combined with the colloidal silver nano-particles solution for $1 \mathrm{~min}$. Table 1 summarizes all treatment conditions. During laser irradiation, the samples were immersed in the colloidal nano-silver particles solution. For the present experimental work of group 4, coating the tooth samples with carbon black prior to laser illumination was found helpful in order to compensate for the lower absorption of the $1064 \mathrm{~nm} \mathrm{Nd}$ : YAG laser to boost the laser effect on the teeth. In real clinical applications, the higher tooth absorption of the Er: YAG laser should be used.

First, the roughness changes and surface topography of the laser-treated enamel surfaces were recognized by using an Atomic Force Microscope (SPM-AA3000, AFMContact mode, Angstrom Advanced INC, USA). This was followed by evaluating the changes in the enamel surface hardness after laser irradiation using the Digital Micro-Vickers hardness tester (TH 715, 2008, China). The indentations on the tooth samples were made at a $500-\mathrm{g}$ load for 15 seconds. $^{28}$ The structural changes in

Table 1. Laser Treatments of the Tooth Sample Groups

\begin{tabular}{cll}
\hline Group & Step 1 Parameters & Step 2 Parameters \\
\hline $\mathbf{1}$ & Control & - \\
$\mathbf{2}$ & 5 pulses-100 mJ Nd: YAG laser + Nano-silver & $3.6 \mathrm{~W}$ Diode laser for $1 \mathrm{~min}$ \\
$\mathbf{3}$ & $500 \mathrm{~mJ} \mathrm{Nd}$ YAG laser + Nano-silver & $3.6 \mathrm{~W}$ Diode laser for $1 \mathrm{~min}$ \\
$\mathbf{4}$ & $500 \mathrm{~mJ} \mathrm{Nd}$ YAG laser+ carbon black & $(3.6 \mathrm{~W}$ diode laser + Nano silver $)$ for $1 \mathrm{~min}$ \\
$\mathbf{5}$ & $3.6 \mathrm{~W}$ Diode laser + Nano-silver & - \\
\hline
\end{tabular}


dental enamel surfaces after the combined treatment were then investigated using scanning electron microscope SEM (Tescan, Vega3, Czech). Energy dispersive x-ray (EDX) (Angstrom Advanced, AIS2300 Multi-function SEM System, USA) was employed to evaluate the chemical composition of the irradiated surfaces and also to determine the $\mathrm{Ca} / \mathrm{P}$ weight percentage ratio of each sample before and after the laser treatments. An artificial de-mineralization solution was prepared from (0.0022 $\mathrm{M}$ of $\mathrm{CaCl}_{2}, 0.0022 \mathrm{M}$ of $\mathrm{NaH}_{2} \mathrm{PO}_{4}, 0.05 \mathrm{M}$ acetic acid, and few grams of $\mathrm{KOH}$ ) to adjust the $\mathrm{PH}$ of the solution to $4.5 .^{29}$ An accurate (4-digit) electric balance (Sartorius Lab Instruments GmbH\&Co.KG, Goettingen, Germany) was used to weigh the samples before and after the demineralization test. The weighed samples were coated with special wax as an acid-resistance, except for a window of approximately $1.5 \times 1.5 \mathrm{~mm}$ on the treated surface. Each sample was then immersed individually in the demineralization solution for 48 hours at $37^{\circ} \mathrm{C}$. The samples were then washed under tap water for 3 minutes and then by deionized water DI, and they were left to dry. Finally, the wax was removed and the samples were weighed and subjected to SEM observation and EDX analysis again. SPSS version 25 was used for data analysis, in which Kruskal-Wallis test was employed to compare all groups after setting $\alpha<0.05$.

\section{Computer Simulation Model}

The laser heating effect profiles can be studied numerically after substituting specific values of the point laser heating source at specific locations. The nanosecond laser pulse duration and low thermal diffusivity of the enamel ensure very shallow penetration depth. The practical picture represents an ellipse, where the width is along its major axis while the depth is along the minor axis. A computer simulation program was constructed to predict the formability of the laser effect in the enamel. The experimental results showed a thermal diffusion depth of approximately $0.09 \mathrm{~mm}$ when using 4 laser pulses, each with $400 \mathrm{~mJ}$. Tables 2 and 3 present thermal constants and laser parameters used in this work.

The laser-treated profile from the computer model (continuous line) and experiment (dotted line) is shown in Figure 1. This figure shows a very good match between

Table 2. Thermal Constants of Enamel

\begin{tabular}{ccc}
\hline $\begin{array}{c}\text { Thermal conductivity } \\
\left(\mathbf{W} /\left(\mathbf{m m}^{\circ} \mathbf{C}\right)\right)\end{array}$ & $\begin{array}{c}\text { Thermal diffusivity } \\
\left(\mathbf{m m}^{2} / \mathbf{s}\right)\end{array}$ & $\begin{array}{c}\text { Melting } \\
\text { point }\left(\mathrm{T}_{\mathbf{m}}\right)\end{array}$ \\
\hline $0.9 \times 10^{-6}$ & 0.5 & 840 \\
\hline
\end{tabular}

Table 3. Nd: YAG Laser Parameters

\begin{tabular}{ccccccc}
\hline $\begin{array}{c}\text { No. of } \\
\text { Laser } \\
\text { Pulses }\end{array}$ & $\begin{array}{c}\text { Laser } \\
\text { Power } \\
(\mathbf{W})\end{array}$ & $\begin{array}{c}\text { Travel } \\
\text { Speed } \\
(\mathbf{m m} / \mathbf{s})\end{array}$ & $\begin{array}{c}\text { Laser } \\
\text { Intensity } \\
\text { W.mm-2 }\end{array}$ & $\begin{array}{c}\text { Max. } \\
\text { Width } \\
(\mathbf{m m})\end{array}$ & $\begin{array}{c}\text { Laser } \\
\text { Diffusion } \\
\text { Depth }(\mathbf{m m})\end{array}$ & $\begin{array}{c}\text { Affected } \\
\text { Area } \\
\left(\mathbf{m m} \mathbf{m}^{2}\right)\end{array}$ \\
\hline 4 & $4 \times 10^{7}$ & $10^{8}$ & $8 \times 10^{7}$ & 0.8 & $90 \times 10^{-3}$ & 0.5 \\
\hline
\end{tabular}

the experiment and the model, that is, a good prediction of the laser-treated volume before giving the actual treatment.

\section{Results}

The experimental and simulated width and depth of the laser-treated tooth enamel are shown in Figure 2. The SEM image of group 3 samples revealed some fused areas with deposits on the enamel surface as shown in Figure 2C. Figure $2 \mathrm{D}$ represents a treatment of one sample in group 4. Figure $2 \mathrm{E}$ demonstrates the smoother laser-treated surface of a sample in group 5 .

Figure 2F demonstrates a laser-affected depth of approximately $0.09 \mathrm{~mm}$ cross-section of an enamel sample treated with 4 pulses of $400 \mathrm{~mJ} \mathrm{Nd}$ : YAG laser.

The atomic force microscope (AFM) analysis images demonstrated significant changes in the topography of the treated enamel surfaces compared to the control samples (Figure 3).

The AFM results of the treated enamels showed small roughness spikes, indicating the positive effect of silver nanoparticles, as seen in Figure $4 \mathrm{a}$.

Figure $4 \mathrm{~b}$ describes a significant decrease in the enamel grain size which may have resulted from the existence of silver nanoparticles between the enamel grains. Figure $4 \mathrm{c}$ indicates a significant increase in tooth enamel microhardness of the treated enamels compared to the control. Figure $4 \mathrm{c}$ shows the greatest microhardness increase (group 4). Group 5 shows the lowest microhardness increase, as only the low-intensity diode laser and colloidal silver nanoparticles solution were used in the treatment. The silver nanoparticles' weight percentages were acceptable in most treated samples, as seen in Figure 5. In the demineralization test, the enamel

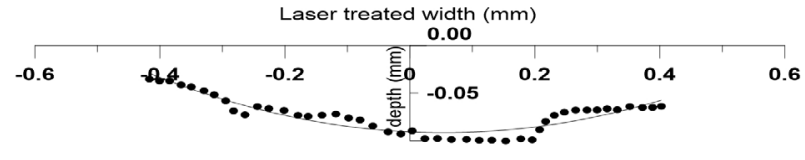

Figure 1. Treated Enamel From the Computer Model (Continuous Line) and Experiment (Dotted Line).
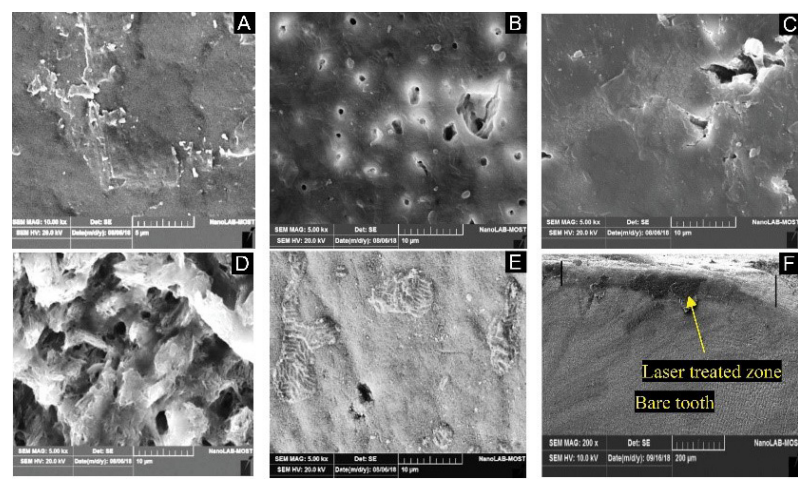

Figure 2. SEM Images of Normal Enamel Surface: (A) Group 1 (Control), (B) Group 2, (C) Group 3, (D) Group 4, (E) Group 5, and (F) Laser-Treated Enamel Depth. 

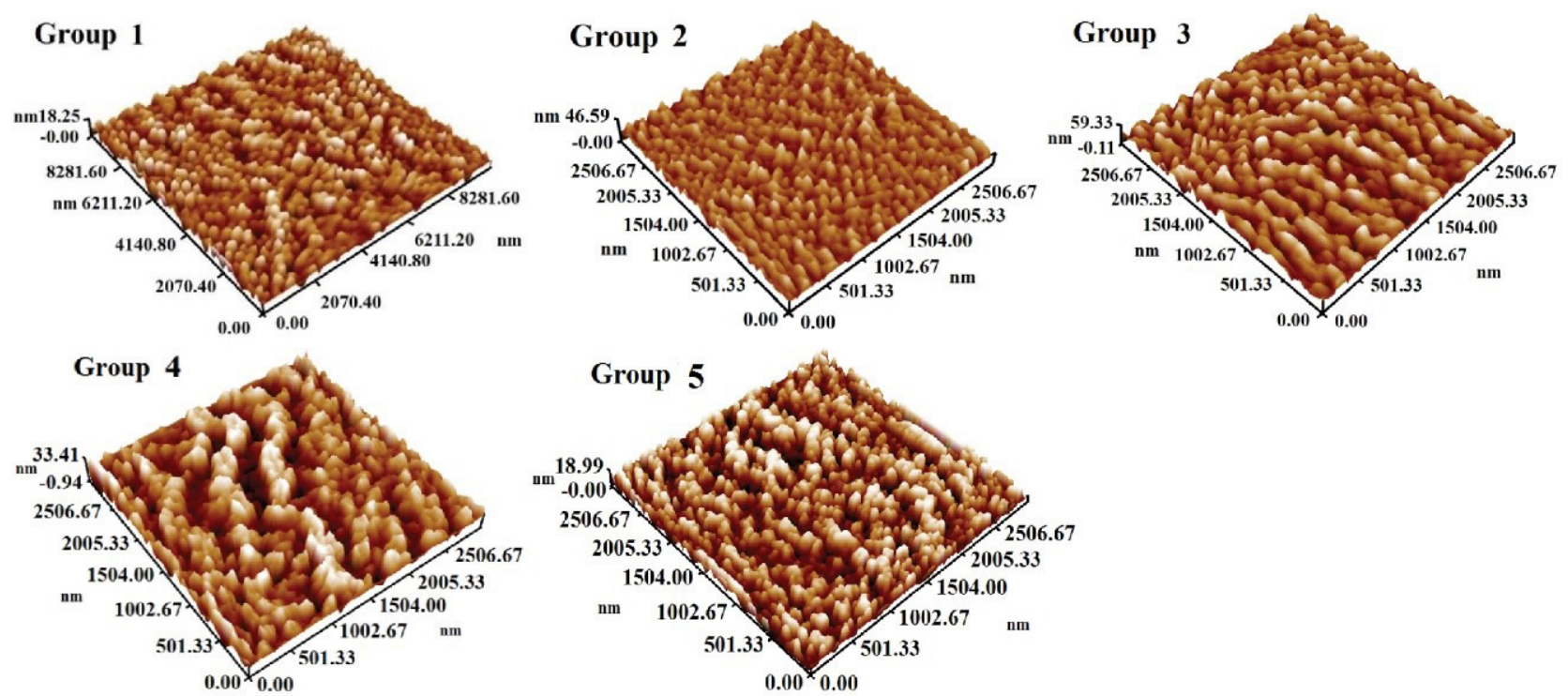

Figure 3. 3D-AFM Topographic Images of the Tooth Samples.
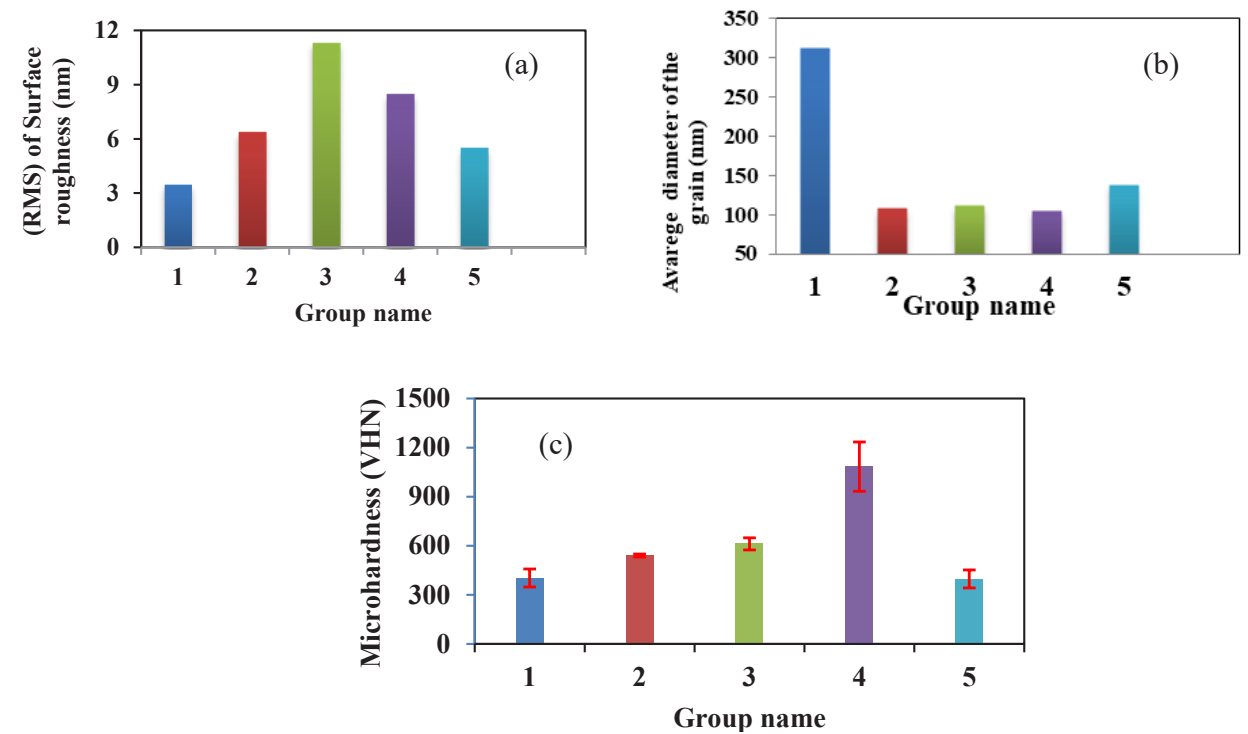

Figure 4. (a) Enamel Surface Roughness, (b) Average Grain Diameter, and (c) Microhardness of the Laser-Treated Groups.
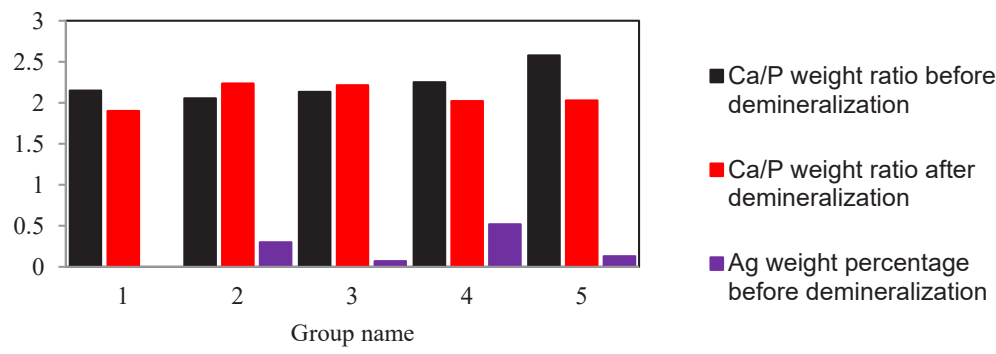

Figure 5. $\mathrm{Ca} / \mathrm{P}$ and $\mathrm{Ag}$ Weight Ratio Before and After the Demineralization.

samples were immersed in the acid solution for 48 hours, during which some minerals were extracted.

Figure 6A describes the SEM images of a demineralized sample from group 1 (control), which demonstrates deep voids on the tooth surface, meaning a large number of minerals extracted from the enamel surface. The SEM images of the treated samples (Figure 6B, C, D), on the other hand, demonstrate the lesser depth of voids.

The SEM images of group 5 samples treated with the diode laser and silver nanoparticles have demonstrated 

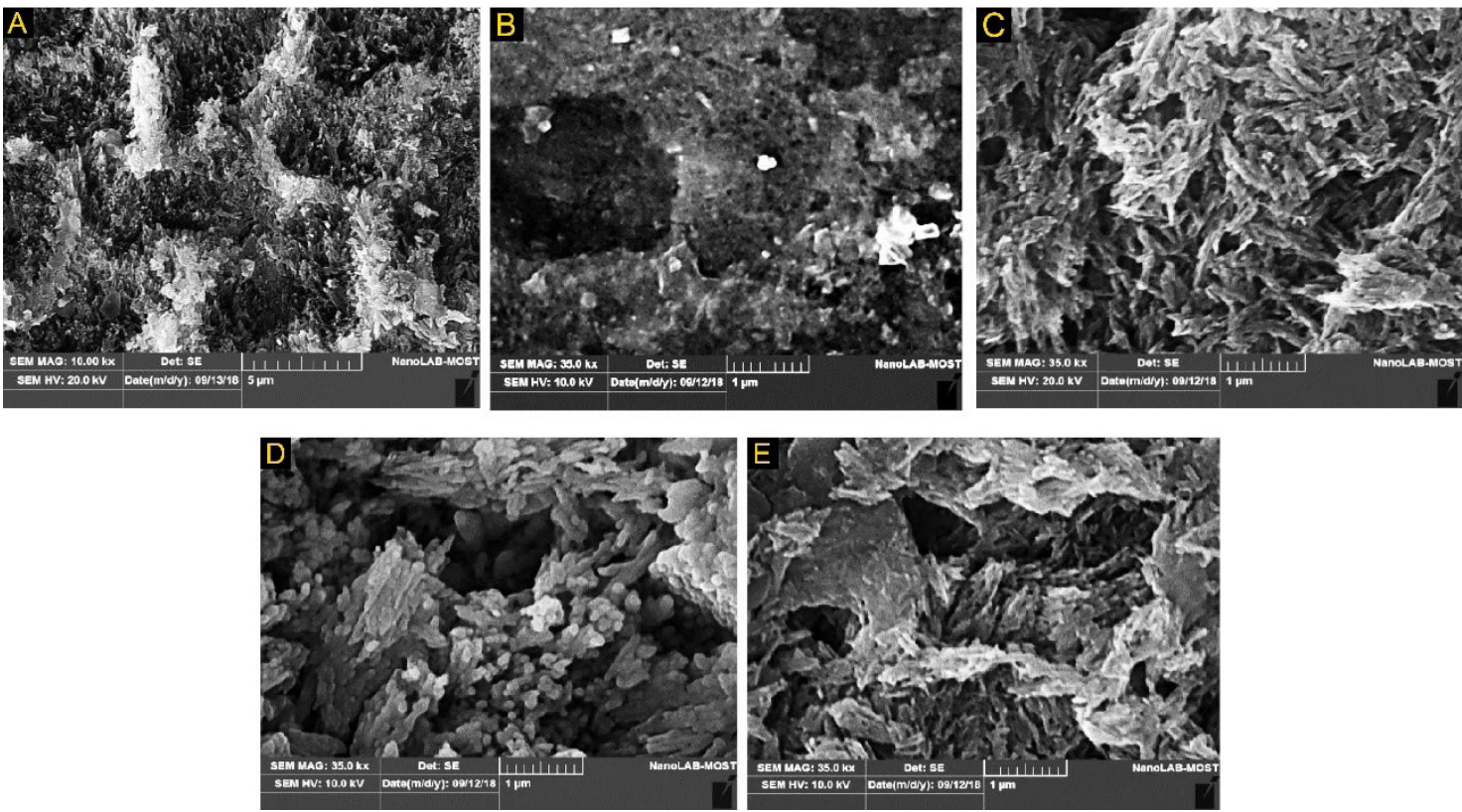

Figure 6. SEM Images of the Samples After Immersing in a De-mineralization Solution for 48 Hours: (A) Group 1, (B) Group 2, (C) Group 3, (D) Group 4, and (E) Group 5.

the least surface changes and voids depth after the demineralization process, as seen in Figure 7.

\section{Statistical Analysis Results}

Roughness

Statistically, there was a significant difference between all groups $P=0.001$ (Table 4 ). The results of the post-hoc multiple comparison between each group and the other are summarized hereunder:

1. There was a significant difference between the 500 mJ Nd: YAG laser + Nano silver + 3.6 W diode laser group and the control group, $P<0.001$.

2. There was a significant difference between the 500 mJ Nd: YAG laser + carbon black+3.6 W diode laser + NS group and the control group, $P=0.009$

3. There was a significant difference between the 5 pulses-100 mJ Nd: YAG laser + Nano-silver +3.6 W diode laser group and the $500 \mathrm{~mJ} \mathrm{Nd:} \mathrm{YAG} \mathrm{laser} \mathrm{+}$ Nano-silver+3.6 W diode laser group, $P=0.012$

4. There was a significant difference between the 500 mJ Nd: YAG laser + Nano-silver + 3.6 W diode laser group and the + NS group, $P=0.004$.

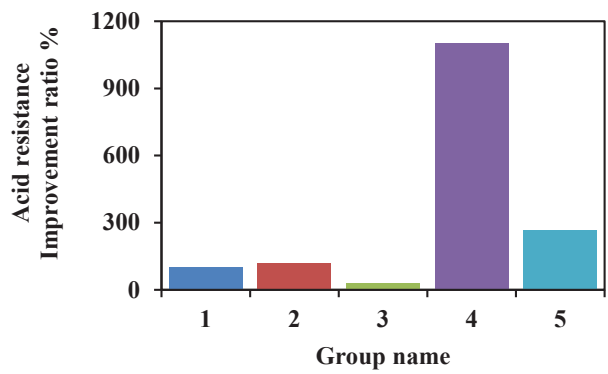

Figure 7. Decay Resistance After Immersion in Demineralization Solution for 48 Hours.

\section{Hardness}

The results of the post-hoc multiple comparison between each group and the other one are summarized to show the significant differences:

1. There was a significant difference between the 500 mJ Nd: YAG laser + Silver NP +3.6 W DL group and the control group, $P=0.010$.

2. There was a significant difference between the 500 mJ Nd: YAG laser + carbon black + 3.6 W DL+ Silver NP group and the control group, $P<0.001$.

3. There was a significant difference between the 5 pulses-100 mJ Nd: YAG laser + Silver NP +3.6 DL group and the $500 \mathrm{~mJ} \mathrm{Nd}$ : YAG laser + carbon black+3.6 W DL+ Silver NP group, $P<0.001$.

4. There was a significant difference between the 500 mJ Nd: YAG laser + Silver NP +3.6 W DL group and the $500 \mathrm{~mJ} \mathrm{Nd}$ : YAG laser + carbon black + 3.6 DL+ Silver NP group, $P<0.001$.

5. There was a significant difference between the 5 pulses-100 mJ Nd: YAG laser + Silver NP +3.6 W DL group and the black+3.6 DL+ Silver NP group, $P<0.001$.

6. There was a significant difference between the $500 \mathrm{~mJ}$ Nd: YAG laser + carbon black + 3.6 W DL+ Silver NP group and the 3.6 W DL + Silver NP group, $P<0.001$

7. There was a significant difference between the $3.6 \mathrm{~W}$ $\mathrm{DL}+$ Silver NP group and the $500 \mathrm{~mJ}$ Nd: YAG laser + Silver N.P +3.6 W DL group, $P=0.015$.

8. There was a significant difference between the 500 mJ Nd: YAG laser + carbon black +3.6 W DL + Silver NP 3.6 W DL + Silver NP group and the 3.6 W DL + Silver NP group; $P<0.001$ (Table 5). 
Table 4. Statistical Analysis of Teeth Surface Hardness

\begin{tabular}{lc}
\hline & VAR00001 \\
\hline Kruskal-Wallis H & 19.621 \\
df & 4 \\
Asymp. Sig. & 0.001 \\
\hline a. Kruskal Wallis Test & \\
b. Grouping Variable: Hardness group &
\end{tabular}

Table 5. Statistical Analysis Result of Teeth Surface Roughness

\begin{tabular}{lc}
\hline & VAR00001 \\
\hline Kruskal-Wallis H & 18.005 \\
df & 4 \\
Asymp. Sig. & 0.001 \\
\hline a. Kruskal-Wallis test & \\
b. Grouping Variable: Roughness group. &
\end{tabular}

\section{Discussion}

The excellent match between experimental and simulated heat distribution inside the tooth enamel for groups 2, 3, 4 , and 5 indicates a possible prediction of the temperature distribution, as shown in Figure 1. The micro-pores of group 2 in Figure 2 appeared at $400^{\circ} \mathrm{C}$ and increased in size and number at $500^{\circ} \mathrm{C} .{ }^{30}$ Glass-like surfaces and columns isolated by voids are seen in Figure 2D, due to the vaporization of water and organic components. ${ }^{31}$ The smooth laser-treated surface shown in Figure 2E may be attributed to the regular fusing of the surface as a result of the continuous operating mode of the diode laser. The low-power diode laser helped to nest some silver particles on the enamel surface by its limited heating effect compared to the Nd: YAG laser. Surface transformations were caused by enamel melting during laser illumination followed by re-crystallization during cooling. When the enamel's temperature reaches $200^{\circ} \mathrm{C}$, intra-crystalline voids may form, and at $350^{\circ} \mathrm{C}$, these voids become very clear and increase in number and size with a temperature until $600^{\circ} \mathrm{C} .{ }^{32}$ The surface grains of the treated enamels, obtained from AFM, in Figure 3, had a regular chain-like arrangement connected by merging the neighboring enamel grains. Laser treatment of the enamel surface has shown high roughness due to laser-induced crystallographic changes. This increased roughness can help to nest restorative silver nanoparticles between the granules of the enamel tissue by the effect of the laser. The incident laser on the enamel is converted into a hightemperature heat which causes optical, morphological, and crystallographic changes in the enamel crystal due to chemical reactions at high temperatures. These changes are induced by organic matrix extension, phase transformation (because of inorganic materials melting), and the blockage of ion diffusion pathways. ${ }^{33}$ After laser illumination, the enamel crystal size after laser illumination (Figure 4b) may change, ${ }^{24}$ and when its temperature rises between $200^{\circ} \mathrm{C}-400^{\circ} \mathrm{C}$, its crystallites become smaller along the a-axis direction of the hexagonal phase. ${ }^{34}$ The hardness increase of enamel shown in Figure 4c was due to sudden laser heating and fast quenching of a thin surface layer of enamel, and to the plasma pressure that is generated by laser ablationshockwave, which pushes inside the enamel tissue during laser irradiation. ${ }^{35,36}$ Furthermore, the changes in crystal size growth and recrystallization of porous enamel, as a result of the high-temperature rise of the surface, can contribute directly to the rise of tooth microhardness. ${ }^{37,38}$ The high microhardness of Figure $4 \mathrm{c}$ was due to the highly light-absorbing carbon black covering its surface during Nd: YAG laser irradiation. When enamel microhardness increases, the tooth abrasion degree becomes lower, leading to higher tooth resistance to decay. ${ }^{38}$ The laser modifications induced in enamel components like organic content of the mineral phases, water, and carbonate would lead to a reduction in the hydroxyapatite lattice stress and the enamel solubility. ${ }^{39}$ In hydroxyapatite crystals, calcium and phosphorus are the main inorganic components of the dental enamel tissue. ${ }^{40}$ During melting and re-solidification, the mineral components are redistributed, leading to a change in the calcium to phosphorus ratio. ${ }^{23}$ In Figure 5 , the $\mathrm{Ca} / \mathrm{P}$ ratio of the decreased enamel, after demineralization, is ascribed to the faster demineralization of the enamel surface in the acidic environment. ${ }^{23}$ After demineralization, the $\mathrm{Ca} / \mathrm{P}$ ratios of groups 2 and 3 became higher than they were before the demineralization, while they became lower for groups 4 and 5, probably due to the possible deposition of silver nanoparticles on $\mathrm{Ca}$ of the enamel surface. At high laser energy, the permeability reduction and penetration of acids deeper in the enamel are caused by chemical and mineral changes. ${ }^{31}$ The $\mathrm{Ca} / \mathrm{P}$ mineral ratio was modified by the laser energy that forms steadier and lesser acid soluble compositions, thus reducing the chances of an acid attack that causes caries. ${ }^{41}$ In laser-heated enamel, when the ratio between mineral to organic components changes, the ratio of $\mathrm{Ca} / \mathrm{P}$ also changes, which could affect permeability, solubility, or adhesive specifications of the enamel tissue. ${ }^{42}$ The high $\mathrm{Ca} / \mathrm{P}$ ratio means high enamel microhardness, that is, high tooth resistance to decay. The treated samples in Figure 6 express a high concentration of minerals on the enamel surface. It also shows a strong interconnection between enamel crystals; leading to a higher acid resistance of the enamel tissues. The use of the Nd: YAG laser causes enamel fusion, melting, recrystallization, and loss of organic matter and carbonate. ${ }^{34}$ These physical and chemical changes result in morphological and chemical modifications in the structure of the treated enamel surface. ${ }^{35,36}$ The microchannels in the enamel layer may be sealed by the melted enamel, and this delays the penetration of acid solution in the enamel tissue and subsequently delays minerals dissolution..$^{23}$ Despite the limited surface changes of group 5 samples (Figure 6E), high surface charge characteristics 
of silver nanoparticles can initiate antimicrobial effects and help to repel the bacteria out. ${ }^{43}$ The SEM images of the treated samples demonstrate changes in the orientations of most enamel rods. They became tangled with one another (see Figures 6C, 6D, and 6E), while they were parallel to each other before laser treatment, as seen in Figure 5 . These changes could reduce the acid penetration in the enamel, leading to an increase in tooth resistance. The results of the weight test, after demineralization, demonstrated a remarkable acid resistance improvement of the laser-treated enamel surfaces compared to the control samples. These signals reduced solubility of the enamel tissues. The highest acid resistance improvement ratio (1100\%) was for group $4(500 \mathrm{~mJ} \mathrm{Nd:} \mathrm{YAG} \mathrm{+} \mathrm{diode}$ laser + silver nanoparticles), as shown in Figure 7. High acid resistance was achieved by the high absorption of the Nd: YAG laser light, after using carbon black, and the tooth surface annealing by the diode laser. This is consistent with the high microhardness value of the same group, as seen in Figure 2F. The crystallographic structure changes of the laser-irradiated enamel tissues, which melt and cool rapidly, begin when the laser energy heats the enamel to a temperature between $100-600^{\circ} \mathrm{C} .{ }^{20}$ At temperatures higher than $600^{\circ} \mathrm{C}, \beta-\mathrm{TCP}$ and $\beta-\mathrm{Ca}_{3}$ $(\mathrm{PO} 4)_{2}$ are generated, with lower solubility against acids. ${ }^{44}$ Carbonate loss forms carbonated hydroxyapatite (enamel Apatite) that lowers the enamel demineralization. ${ }^{45} \mathrm{Crystal}$ size increases at the same time because of the thermal recrystallization. ${ }^{24,42,46}$ Laser intensity, absorption depth, and laser pulse duration are the most important parameters to complete carbonate removal. ${ }^{47}$ Chemical changes that occur after laser illumination can affect ions' diffusion and dissolution of dental enamel during the acid attack by losing its transportation elements (protein and water), which makes it more stable and resistant against decay.

\section{Conclusion}

The addition of antibacterial silver nanoparticles on the laser-modified enamel surface improved the decay resistance. The surface of the treated enamel samples, with four $400 \mathrm{~mJ} \mathrm{Nd:} \mathrm{YAG} \mathrm{laser} \mathrm{pulses,} \mathrm{formed} \mathrm{regular}$ inter-connected chain-like merged grains. These laserinduced modifications in enamel components led to a reduction in the hydroxyapatite lattice stress and the enamel solubility. The rise of the $\mathrm{Ca} / \mathrm{P}$ ratio increased the enamel microhardness, resulting in an increased tooth resistance to decay. The micro-channels in the enamel were sealed by the melted enamel which helped to delay the penetration of acid solution, subsequently delaying minerals dissolution. The weight loss test, after demineralization, indicated reduced enamel solubility. The computer model showed a very good match with the experimental findings, which means a possible prediction of the laser-treated profile prior to laser treatment. To the best of our knowledge, the present findings are new and constitute an excellent addition to previous tooth antidecay works.

\section{Ethical Considerations}

Not applicable.

\section{Conflict of Interests}

The authors declare that they have no known competing financial interests or personal relationships that could have appeared to influence the work reported in this paper.

\section{Funding}

This research received no external funding.

\section{References}

1. Moore WEC, Moore LVH. The bacteria of periodontal diseases. Periodontology. 2000; 5(1):66-77. doi. org/10.1111/j.1600-0757.1994.tb00019.x.

2. Loesche WJ. Role of Streptococcus mutans in human dental decay. Microbiol Rev. 1986;50(4):353-380. doi:10.1128/ mr.50.4.353-380.1986

3. Walsh LJ. The current status of laser applications in dentistry. Aust Dent J. 2003;48(3):146-55; quiz 198. doi: 10.1111/j.18347819.2003.tb00025.x

4. Marinho VC, Worthington HV, Walsh T, Clarkson JE. Fluoride varnishes for preventing dental caries in children and adolescents. Cochrane Database Syst Rev. 2013;(7):CD002279. doi: 10.1002/14651858.CD002279.pub2.

5. Rosenblatt A, Stamford TC, Niederman R. Silver diamine fluoride: a caries "silver-fluoride bullet". J Dent Res. 2009;88(2):116-25. doi: 10.1177/0022034508329406.

6. Santos VE Jr, Vasconcelos Filho A, Targino AG, Flores MA, Galembeck A, Caldas AF Jr, Rosenblatt A. A new "silverbullet" to treat caries in children--nano silver fluoride: a randomised clinical trial. J Dent. 2014;42(8):945-51. doi: 10.1016/j.jdent.2014.05.017.

7. Attin T, Hartmann O, Hilgers RD, Hellwig E. Fluoride retention of incipient enamel lesions after treatment with a calcium fluoride varnish in vivo. Arch. Oral Biol. 1995;40(3): 169-74. dio: 10.1016/0003-9969(95)98804-8.

8. Stern RH, Sognnaes RF. Laser inhibition of dental caries suggested by first tests in vivo. J Am Dent Assoc. 1972; 85(5):1087-90. doi: 10.14219/jada.archive.1972.0491.

9. Zulkifli NS, Suhaimi FM, Khairul Azhar Razab AM, Suhaimi Jaafar M, Mokhtar N. The use of Nd:YAG laser for ablation of dental material. IACSIT Press, Singapore.2015; 81(8):40-47. doi: 10.7763/IPCBEE.2015.V81.8.

10. Wakabayashi H, Hamba M, Matsumoto K, Tachibana H. Effect of irradiation by semiconductor laser on responses evoked in trigeminal caudal neurons by tooth pulp stimulation. Lasers Surg Med. 1993;13(6):605-10. doi: 10.1002/lsm.1900130603.

11. Westerman GH, Flaitz CM, Powell GL, Hicks MJ. Enamel caries initiation and progression after argon laser irradiation: in vitro argon laser systems comparison. J Clin Laser Med Surg. 2002;20(5):257-62. doi: 10.1089/10445470260420768.

12. Ki-Young Nam. In vitro antimicrobial effect of the tissue conditioner containing silver nanoparticles. $J A d v$ Prosthodont. 2011; 3(1): 20-24. doi: 10.4047/jap.2011.3.1.20.

13. Durner J, Stojanovic M, Urcan E, Hickel R, Reichl FX. Influence of silver nano-particles on monomer elution from light-cured composites. Dent Mater. 2011;27(7):631-6. doi: 10.1016/j.dental.2011.03.003. 
14. Chen H, Gu L, Liao B, Zhou X, Cheng L, Ren B. Advances of Anti-Caries Nanomaterials. Molecules.2020;25(21):5047. doi: 10.3390/molecules25215047.

15. Carrouel F, Viennot S, Ottolenghi L, Gaillard C, Bourgeois D. Nanoparticles as Anti-Microbial, Anti-Inflammatory, and Remineralizing Agents in Oral Care Cosmetics: A Review of the Current Situation. Nanomaterials (Basel). 2020; 10(1):140. doi:10.3390/nano10010140.

16. Litvack F, Grundfest WS, Papaioannou T, Mohr FW, Jakubowski AT, Forrester JS. Role of laser and thermal ablation devices in the treatment of vascular diseases. Am J Cardiol. 1988; 61(14):81G-86G. doi: 10.1016/s00029149(88)80038-9.

17. Vahl J, Pfefferkorn G. Electron optic studies of changes in the dental hard substance caused by laser irradiation. Dtsch Zahnarztl Z. 1967; 22(2):386-94. [German]

18. Stern RH, Renger HL, Howell FV. Laser effects on vital dental pulps. Br Dent J 1969; 127:26-28.

19. Tagomori S, Morioka T. Combined effects of laser and fluoride on acid resistance of human dental enamel. Caries Res. 1989; 23(4):225-31. doi: 10.1159/000261182.

20. Kuroda S, Fowler BO. Compositional, structural, and phase changes in in vitro laser-irradiated human tooth enamel. Calcif Tissue Int. 1984; 36(4):361-9. doi: 10.1007/BF02405347.

21. Fowler BO, Kuroda S. Changes in heated and in laserirradiated human tooth enamel and their probable effects on solubility. Calcif Tissue Int. 1986; 38(4):197-208. doi: 10.1007/ BF02556711.

22. Kato IT, Kohara EK, Sarkis JE, Wetter NU. Effects of 960-nm diode laser irradiation on calcium solubility of dental enamel: an in vitro study. Photomed Laser Surg. 2006; 24(6):689-93. doi: 10.1089/pho.2006.24.689.

23. Ferreira JM, Palamara J, Phakey PP, Rachinger WA, Orams HJ. Effects of continuous-wave CO2 laser on the ultrastructure of human dental enamel. Arch Oral Biol. 1989; 34(7):551-62. doi: 10.1016/0003-9969(89)90094-0.

24. Kantola S, Laine E, Tarna T. Laser-induced effects on tooth structure. VI. X-ray diffraction study of dental enamel exposed to a $\mathrm{CO}_{2}$ laser. Acta Odontol Scand. 1973; 31(6):36979. doi: 10.3109/00016357309002524.

25. Yamamoto K, Muhammad NA, Higuchi WI, Fox JL. The influence of dodecylamine hydrochloride on the dissolution kinetics of heat-treated hydroxyapatite samples. J Colloid and Interface Science. 1986; 110: 459-467. doi: 10.1016/00219797(86)90399-1

26. Bahar A, Tagomori S. The effect of normal pulsed Nd-YAG laser irradiation on pits and fissures in human teeth. Caries Res. 1994; 28(6):460-7. doi: 10.1159/000262021.

27. Nawrocka A, Łukomska-Szymańska M. Extracted human teeth and their utility in dental research. Recommendations on proper preservation: A literature review. Dent Med Probl. 2019; 56(2):185-190. doi: 10.17219/dmp/105252.

28. Lin CP, Lee BS, Kok SH, Lan WH, Tseng YC, Lin FH. Treatment of tooth fracture by medium energy $\mathrm{CO}_{2}$ laser and DP-bioactive glass paste: thermal behavior and phase transformation of human tooth enamel and dentin after irradiation by $\mathrm{CO}_{2}$ laser. J Mater Sci Mater Med. 2000; 11(6):373-81. doi: 10.1023/a:1008986008510.

29. Vander Voort G. Microindentation hardness testing. In: H. Kuhn, D. Medlin, eds. ASM Handbook. ASM International; 2000: 221-231. doi: 10.1361/asmhba0003272

30. Gouvêa DB, Santos NMD, Pessan JP, Jardim JJ, Rodrigues JA. Enamel Subsurface Caries-Like Lesions Induced in Human Teeth By Different Solutions: A TMR Analysis. Braz Dent J.
2020;31(2):157-163. doi: 10.1590/0103-6440202003123.

31. Rohanizadeh R, LeGeros RZ, Fan D, Jean A, Daculsi G. Ultrastructural properties of laser-irradiated and heattreated dentin. J Dent Res. 1999;78(12):1829-35. doi: 10.1177/00220345990780121001.

32. Brandão $\mathrm{CB}$, Corona SAM, Torres CP, Côrrea-Marques AA, Saraiva MCP, Borsatto MC. Efficacy of CO lasers in preventing dental caries in partially erupted first permanent molars: a randomized 18-month clinical trial. Lasers Med Sci. 2020;35(5):1185-1191. doi: 10.1007/s10103-020-02967-7.

33. Zach L, Cohen G. Pulp Response to externally applied heat. Oral Surg Oral Med Oral Pathol. 1965;19:515-30. doi: 10.1016/0030-4220(65)90015-0.

34. Hamoudi WK, Ismail RA. Welding of similar and dissimilar wires with 10 ms laser pulses. Int J Join Mat.1995; 7: 124-128.

35. Sato K. Relation between acid dissolution and histological alteration of heated tooth enamel. Caries Res. 1983; 17(6):4905. doi: 10.1159/000260708.

36. Tagomori S, Iwase T. Ultrastructural change of enamel exposed to a normal pulsed Nd-YAG laser. Caries Res. 1995; 29(6):513-20. doi: 10.1159/000262123.

37. Palamara J, Phakey PP, Rachinger WA, Orams HJ. The ultrastructure of human dental enamel heat-treated in the temperature range 200 degrees $\mathrm{C}$ to 600 degrees C. J Dent Res. 1987;66(12):1742-7. doi: 10.1177/00220345870660120901.

38. Kwon YH, Kwon OW, Kim HI, Kim KH. Nd:YAG laser ablation and acid resistance of enamel. Dent Mater J. 2003; 22(3):404-11. doi: 10.4012/dmj.22.404.

39. Sakae T. X-ray diffraction and thermal studies of crystals from the outer and inner layers of human dental enamel. Arch Oral Biol. 1988; 33(10):707-13. doi: 10.1016/00039969(88)90003-9.

40. Charles S. Montross, Tao Wei, Ye L, Clark G, Mai YW. Laser shock processing and its effects on microstructure and properties of metal alloys: a review. Int J of Fatigue. 2002; 24(10): 1021-1036. doi: 10.1016/S0142-1123(02)00022-1.

41. El Assal DW, Saafan AM, Moustafa DH, Al-Sayed MA. The effect of combining laser and nanohydroxy-apatite on the surface properties of enamel with initial defects. J Clin Exp Dent. 2018; 10(5):e425-e430. doi: 10.4317/jced.54371.

42. Valério RA, Rocha CT, Galo R, Borsatto MC, Saraiva MC, Corona SA. CO2 laser and topical fluoride therapy in the control of caries lesions on demineralized primary enamel. Sci World J. 2015; 2015:547569. doi: 10.1155/2015/547569.

43. Eisner K. Prozesstechnologische Grundlagen zur Schockverfestigung von metallischen Werkstoffen mit einem kommerziellen Excimerlaser. Dissertation, Universität Erlangen, 1998. [German]

44. Attin T, Koidl U, Buchalla W, Schaller HG, Kielbassa AM, Hellwig E. Correlation of microhardness and wear in differently eroded bovine dental enamel. Arch Oral Biol. 1997;42(3):243-50. doi: 10.1016/0003-9969(06)00073-2.

45. Westerman GH, Ellis RW, Latta MA, Powell GL. An in vitro study of enamel surface microhardness following argon laser irradiation and acidulated phosphate fluoride treatment. Pediatr Dent. 2003;25(5):497-500.

46. Dilber E, Malkoc MA, Ozturk AN, Ozturk F. Effect of various laser irradiations on the mineral content of dentin. Eur J Dent. 2013;7(1):74-80.

47. Sadony, D.M., Abozaid, H.Es. Antibacterial effect of metallic nanoparticles on Streptococcus mutans bacterial strain with or without diode laser (970 nm). Bull Natl Res Cent. 2020; 44(1):1-6. doi:10.1186/s42269-019-0262-z. 